\title{
In Response to "Preoperative Angiotensin Axis Blockade Therapy, Intraoperative Hypotension, and the Risks of Postoperative Acute Kidney Injury"
}

\author{
Eileen Hennrikus, MD, FACP' ${ }^{1}$, Berend Mets, MB, PhD, FRCA²
}

${ }^{1}$ Department of Internal Medicine, Pennsylvania State University College of Medicine and Milton S. Hershey Medical Center, Hershey, Pennsylvania; ${ }^{2}$ Department of Anesthesiology, Pennsylvania State University College of Medicine and Milton S. Hershey Medical Center, Hershey, Pennsylvania.

We are pleased to note the response of Onuigbo et al. to our article demonstrating an increase in acute kidney injury (AKI) associated with angiotensin axis blockade $(\mathrm{AAB})$ in major orthopedic surgery. ${ }^{1}$ Like Onuigbo et al., we also noted that intraoperative hypotension and $\mathrm{AAB}$ are associated with $\mathrm{AKI} .^{2}$ In addition, we found that $\mathrm{AAB}$-associated $\mathrm{AKI}$ occurred independently of intraoperative hypotension. Because of our findings, we withhold angiotensin-converting enzyme inhibitors and angiotensin receptor blockers on the day of surgery in all patients presenting for major orthopedic surgery whose blood pressure is well controlled preoperatively. We were concerned that this practice might increase the incidence of pre- and postoperative hypertension in such patients, but we have been reassured by a recent article demonstrating that this does not occur in outpatient surgical patients. ${ }^{3}$
We caution, however, that the common sense approach of stopping AAB preoperatively to avoid possible AKI still requires evaluation by a properly conducted randomized controlled trial. Because of the prolonged systemic halflife and duration of tissue activity ( $>24$ hours) of many $\mathrm{AAB}$ agents, ${ }^{4}$ the required preoperative cessation period of $\mathrm{AAB}$ may vary considerably.

\section{References}

1. Nielson E, Hennrikus E, Lehman E, Mets B. Angiotensin axis blockade, hypotension, and acute kidney injury in elective major orthopedic surgery. J Hosp Med. 2014;9:283-288.

2. Onuigbo MA, Onuigbo NTC. A second case of "quadruple whammy" in a week in a northwestern Wisconsin hospital. BMJ. 2013;346:f678.

3. Twersky RS, Goel V, Narayan P, Weedon J. The risk of hypertension after preoperative discontinuation of angiotensin-converting enzyme inhibitors or angiotensin receptor antagonists in ambulatory and same-day admission patients. Anesth Analg. 2014;118:938-944.

4. Mets B. Management of hypotension associated with angiotensin-axis blockade and general anesthesia administration. J Cardiothorac Vasc Anesth. 2013;27:156-167. 